\title{
¿Cómo analizar discursos de 140 caracteres? Propuesta metodológica para el estudio del discurso político de campaña en Twitter a partir del análisis estratégico con una perspectiva multimodal y crítica
}

\author{
Aniela Ventura \\ Consejo Nacional de Ciencia y Técnica (CONICET) - Instituto de \\ Lingüística de la Facultad de Filosofía y Letras de la Universidad de Buenos \\ Aires
}

This article presents a methodology for the collection and analysis of corpus of political discourses published on Twitter. It has been drawn up in an ongoing doctoral research that seeks to report the discursive strategies used in the official accounts of the Argentine presidential candidates during the 2015 electoral campaign. This methodology is based on the strategic analysis of the discourse (Menéndez 2000, 2005, 2009, 2010, 2012) with a multimodal perspective (Kress \& Van Leeuwen 2001). This expects, in the first place, the description of the corpus from a grammatical analysis with a functional systemic base (Halliday 1970, 1985, Halliday \& Matthiessen 2014, Kress \& Van Leeuwen 2001, Kress \& Van Leeuween 2006 [1996]) and pragmatic discursive studies (Lavandera 1992, Martin \& White 2005, Sperber \& Wilson 1994[1986]). And, secondly, the relation between the results obtained by these analysis in order to look for recurrences that allow to rebuild the produced discursive strategies. Finally, it seeks to achieve a critical analysis (Fairclough 2003) of these strategies, which allows to understand the campaign political discourse on Twitter in terms of discursive practices and analyze its influence on current political practices.

Keywords: political discourse - Twitter - methodology - strategic discourse analysis - multimodality

\section{Introducción}

Desde el año 2008, cuando el equipo de campaña de Barack Obama la adoptó como uno de sus principales medios de comunicación con el electorado (Delany 
2009), el uso de la red social Twitter por parte de los candidatos políticos de los países occidentales no ha parado de crecer. Las particularidades de este fenómeno han dado lugar al desarrollo de nuevas prácticas discursivas (Fairclough 2003) y lo han convertido en el objeto de estudio de diversas disciplinas como la ciencia política, los estudios culturales y las ciencias de la comunicación (Calvo 2015, Delany 2009, Fages-Ramió 2008, Graham, y otros 2013, Jungherr 2016, Mangone 2012, Rojas 2012, Sarlo 2011, Slimovich 2014). En los campos de la lingüística de corpus y el análisis del discurso, por su parte, resultan cada vez más frecuentes los estudios de estas nuevas prácticas desde distintas perspectivas y con múltiples objetivos (Alcántara-Plá y Ruiz-Sánchez 2018, Mancera Rueda y Pano Alamán 2013, Mazzuchino 2017, Ques 2012).

Sin embargo, no se han relevado aún investigaciones que aborden el discurso político en Twitter desde el marco del análisis estratégico ni con una perspectiva multimodal, como aquí lo proponemos, y son aún escasas las publicaciones que se detienen a reflexionar sobre lo que implica, a nivel metodológico, el abordaje de este nuevo objeto de estudio. Consideramos que esto último resulta un aporte de relevancia para el intercambio académico. Por lo tanto, presentaremos a continuación la metodología cualitativa desarrollada en una investigación doctoral en curso cuyo objetivo general es explicar las nuevas prácticas discursivas (Fairclough 2003) desplegadas en las cuentas oficiales de Twitter de los candidatos presidenciales argentinos durante la campaña electoral 2015. Ello conlleva: comprender la instauración de Twitter como medio legítimo de producción y difusión del discurso político, explicar cómo se reformula la multidestinación del discurso político (Verón 1987) en este medio, analizar la configuración que se realiza de los candidatos en tanto sujetos discursivos (Menéndez 2009, 2012) en sus cuentas oficiales y cómo ello contribuye a la configuración de sus imágenes (Goffman, 1970 [1967]), estudiar las estrategias discursivas (Menéndez 2000, $2005,2009,2012)$ que se despliegan con la finalidad de argumentar respecto de diversos temas durante la campaña, y aquellas generadas para amenazar la imagen de los contradestinatarios y polemizar con ellos.

\section{Desarrollo}

\subsection{Una breve referencia sobre nuestro marco teórico}

Nuestra investigación se enmarca en el análisis estratégico del discurso (AED) (Menéndez 2000, 2005, 2009, 2012) con una perspectiva multimodal que es compatible y complementaria con el análisis crítico del discurso (ACD). Esto nos permitirá alcanzar una interpretación crítica (Fairclough 1993, 2000, 2003) del 
discurso de campaña de los candidatos en Twitter. El complemento de estas dos perspectivas de análisis nos lleva a definir los discursos como unidades multimodales (Kress y Van Leeuwen 2001, 2002, 2006 [1996]), que se encuentran inmersas en procesos de producción e interpretación (prácticas discursivas) y en circunstancias institucionales y organizativas asociadas con áreas particulares de la vida social (prácticas sociales) (Fairclough 1993), en relación con las cuales causan efectos materiales e ideológicos. Al producir discursos, los hablantes, en tanto sujetos discursivos, despliegan estrategias: optan y combinan una serie de recursos gramaticales pertenecientes a distintos sistemas semióticos con otros de carácter pragmático-discursivo "para lograr una finalidad de la manera más eficaz posible" (Menéndez 2000, 219). Dichas estrategias pueden ser reconstruidas a partir de un análisis textual de base sistémico-funcional (Halliday 1970, 1985, Halliday y Matthiessen 2014) con una perspectiva multimodal (Kress y Van Leeuwen 2001), en complemento con aportes de estudios pragmático-discursivos como el de la valoración (Martin y White 2005) y los supuestos y significados implícitos (Sperber y Wilson 1994 [1986] ). Esto permite analizar la dependencia sociocultural del uso de los distintos sistemas semióticos en situaciones particulares y las intenciones comunicativas de los participantes, a partir de la combinación de los recursos que estos sistemas proveen (Menéndez 2000, 2005, 2009, 2012).

\subsection{Desarrollo de una etnografía virtual}

Este marco teórico presupone un conocimiento, por parte del analista, del contexto de cultura y el contexto de situación (Halliday y Matthiessen 2014), así como la posibilidad de reponer los contextos socio-cognitivos (Sperber y Wilson 1994 [1986]) puestos en juego. Dada la relativa novedad y la especificidad de nuestro objeto de estudio, el acceso a este conocimiento requirió del desarrollo de una etnografía virtual estratégicamente orientada ${ }^{1}$ (Hine 2004) que abarcó dos períodos: el de la campaña presidencial argentina 2011 y el de la campaña $2015^{2}$, durante los que se siguió a las cuentas oficiales de los tres principales candidatos

\footnotetext{
${ }^{1}$ Se denomina de esta manera, dado que el fin último del estudio no es el desarrollo de la etnografía propiamente dicha.

${ }^{2}$ Estas periodizaciones se iniciaron, en ambos casos, el día en que los partidos presentaron las listas de precandidatos para las elecciones primarias y concluyeron, en el caso 2011, cuando la Cámara Nacional Electoral publicó los resultados del escrutinio definitivo de las elecciones presidenciales y, en el 2015, el día en que se llevó a cabo la segunda vuelta de la elección presidencial (ballotage).
} 
a presidente de cada elección y las de sus co-partidarios más representativos. Asimismo, se sondearon aleatoriamente distintos medios masivos tradicionales a los fines de registrar aquellos hechos de la coyuntura socio-política que pudieran resultar significativos para el posterior análisis de corpus. A partir de ello, se realizó un registro etnográfico cuya reformulación permitió caracterizar a Twitter como medio y dar cuenta de sus potencialidades de uso y sus modificaciones a lo largo del tiempo, a los fines de enmarcar el análisis discursivo y explicar la legitimación de esta red social como medio para la producción y difusión del discurso político en Argentina.

El desarrollo de una etnografía virtual y la conformación de corpus a partir de datos disponibles en Internet, requiere realizar consideraciones de índole ética tales como: evaluar el carácter público de la información, la pertinencia de solicitar consentimientos informados y la preservación de la identidad de los sujetos de estudio (Beaulieu y Estalella 2012, De Matteis 2014, Ess y Jones 2004, Markham y Buchanan 2012, Rivers y Lewis 2014). No obstante, tal como lo plantean Beaulieu y Estalella (2012) y De Matteis (2014), cada investigador es responsable de revisar los principios éticos en función de su objeto y comunidad de análisis. En nuestra investigación, trabajamos únicamente con material producido y difundido en Twitter - una red social que desde su política de privacidad enfatiza su carácter público- a través de los perfiles abiertos ${ }^{3}$ y oficiales de candidatos presidenciales. Entendemos a este objeto de estudio en términos de discurso político público (Raiter 2009): se trata de enunciados producidos para ser difundidos y consumidos por una audiencia amplia. Por lo tanto, tal como sucede con discursos de esta clase producidos en cualquier otro medio - actos partidarios, televisión, spots de campaña, etc.- no se considera necesario un consentimiento informado para utilizarlos en una investigación. Respecto del resguardo de la identidad de los sujetos, no solo se trata de figuras públicas cuya identidad no suele ser resguardada en ningún estudio de esta clase, sino que es necesario identificarlos y comprender su historia política, afiliación partidaria y participación en distintos momentos de la campaña para poder explicar las variables contextuales que hacen a las prácticas discursivas analizadas.

\subsection{Constitución del corpus}

A partir del relevamiento etnográfico, se llevó a cabo, además, la obtención de muestras para la posterior conformación de corpus. Recolectamos todos los tuits

\footnotetext{
${ }^{3}$ Twitter brinda la posibilidad de crear cuentas privadas de acceso restringido solo a usuarios autorizados. No hacer uso de esta opción implica que cualquier internauta pueda leer lo que se publica en dicha red social.
} 
publicados - durante el período correspondiente a la campaña 2015- en la cuenta oficial de los tres candidatos presidenciales con mayor intención de voto: Mauricio Macri, Daniel Scioli y Sergio Massa; y todas las publicaciones realizadas por estos políticos en otros medios, a las que se dirigiera mediante hipervínculos presentados en sus micromensajes ${ }^{4}$.

Si bien existen aplicaciones y softwares para la descarga de tuits (como Kwitty o Tweet Archivist) decidimos operar de manera manual a los fines de resguardar el corpus en distintos formatos y para realizar, en simultáneo con la recopilación de muestras, el registro etnográfico de cualquier interacción de los políticos que pudiera resultarnos significativa. Los métodos mediante los cuales conformamos el corpus fueron dos: en primer lugar, con la herramienta "captura de pantalla de página entera" de Firefox, resguardamos - como archivo PNG- cada tuit de los candidatos con todas las respuestas brindadas por otros usuarios. Esto nos permitió: preservar el formato original de los textos -especialmente de aquellos con fotografías- para su posterior análisis multimodal; resguardar información contextual de cada tuit brindada por la plataforma como la fecha y hora exacta de emisión y la cantidad de retuiteos, favoritos y respuestas; registrar las interacciones de otros internautas con los mensajes de los candidatos y -en caso de que las hubiera- las respuestas de los candidatos a las mismas. Si bien dichos intercambios no formaron parte del corpus de nuestra investigación porque nos concentramos en el discurso de los políticos, estas capturas nos permitieron comprobar que en ningún caso los candidatos respondieron públicamente a los comentarios de sus seguidores. Por otra parte, para facilitar la posterior obtención de texto plano necesario para analizar el corpus en UAM Corpus Tool, y a los fines de conservar los hipervínculos publicados en los mensajes con sus accesos directos, copiamos cada uno de los mensajes desde Twitter y los pegamos en archivos Excel (uno por candidato) en los que respetamos su orden e identificamos su fecha de publicación.

Una vez recopiladas las muestras, se detectó que, en varios casos, se publican de manera consecutiva, con minutos de diferencia, desde la cuenta de un mismo candidato, dos o más tuits basados en un mismo tópico, entre los cuales se esta-

\footnotetext{
${ }^{4}$ A partir de una selección de estos materiales multimediales, se conformó un primer corpus subsidiario de videos, publicaciones de Facebook y artículos web. El segundo corpus subsidiario se constituyó a partir de las capturas de pantalla de la página de inicio de las cuentas oficiales de los candidatos. Por una cuestión de extensión, en este trabajo no detallaremos la forma en que se constituyó dicho corpus ni cómo se desarrolla su análisis, pero cabe aclarar que para esto último, se parte de la propuesta metodológica de Kress y Van Leuween (2001, 2002, 2006 [1996]).
} 
blecen diversas relaciones cohesivas (Halliday y Hasan 1976). A modo de ejemplo, se pueden observar los siguientes tuits emitidos desde la cuenta oficial de Daniel Scioli (@DanielScioli) el 22 de agosto de 2015 con escasos minutos de diferencia: "Por primera vez en décadas en la Argentina, podemos decir que bajo todo punto de vista la herencia es muy positiva" (23:12 hs.). "La visión estratégica y los liderazgos de Néstor y Cristina pusieron a salvo a nuestro país y al conjunto de los argentinos" (23:13 hs.) "Aquí no hay improvisación, aquí hay planificación, organización y dirigentes con una probada experiencia" (23:15 hs.). En este caso, además de la cercanía temporal entre un mensaje y otro, observamos el abordaje de un mismo tópico (la gestión de sus co-partidarios en la presidencia) y el uso de recursos de cohesión léxica como la sinonimia (Argentina - nuestro país), la palabra general (dirigentes con una probada experiencia - Néstor y Cristina) y la colocación (herencia positiva - visión estratégica - planificación - probada experiencia), entre otros. Consideramos, por lo tanto, que esos mensajes deben ser estudiados como parte de una unidad mayor a la que denominamos secuencia de tuits.

Entre las muestras recolectadas nos encontramos, por lo tanto, con dos clases de unidades: secuencias y mensajes individuales. El siguiente paso fue numerarlas correlativamente identificando a cada tuit con las iniciales del candidato, la secuencia a la que pertenece y el número de mensaje que le corresponde según el orden de publicación (por ejemplo, las muestras previamente presentadas fueron rotuladas como: DS31-61, DS31-62 y DS31-63). Luego, se clasificó a todas las muestras según el tópico predominante en cada una. Detectamos nueve temáticas generales: 1) los prodestinatarios, 2) el candidato, 3) los paradestinatarios, 4) los contradestinatarios $\left.^{5}, 5\right)$ la descripción y/o evaluación del presente, 6) las propuestas o promesas de campaña, 7) las acciones de gobierno, 8) la agenda de campaña -actos públicos y presencia en medios- y 9) saludos o conmemoraciones. En la siguiente tabla, se puede observar el total de unidades por candidato y su clasificación en tópicos:

Tabla 1. Cantidad de unidades por candidato y tópico

\begin{tabular}{lllll}
\hline Tópico & \multicolumn{3}{l}{ Cantidad de unidades por can- } \\
& $\begin{array}{l}\text { didato } \\
\end{array}$ & Macri & Scioli & Massa \\
\hline 1. Prodestinatarios & 70 & 43 & 62
\end{tabular}

\footnotetext{
${ }^{5}$ Los conceptos de pro-, para- y contradestinatario, son tomados de la concepción de multidestinación del discurso político de Verón (1987).
} 
2. El candidato

3. Paradestinatarios

4. Contradestinatarios

5. El presente

6. Promesas o propuestas

7. Acciones de gobierno

8. Agenda de campaña

\begin{tabular}{llll} 
& 57 & 92 & 21 \\
& 128 & 123 & 28 \\
& 50 & 67 & 60 \\
& 84 & 37 & 33 \\
& 196 & 208 & 124 \\
& 5 & 32 & 2 \\
Acciones de campo & 55 & 104 & 69 \\
Presencia en medios & 50 & 100 & 56 \\
& 10 & 10 & 3 \\
\hline
\end{tabular}

Para la conformación del corpus, se decidió trabajar con las unidades clasificadas bajo los tópicos 1 a 7 por ser las que muestran de manera evidente la combinación de los dos tipos de recursos involucrados en la conformación de estrategias. Para conformar un corpus acotado, posible de ser abordado desde el marco teóricometodológico elegido, se seleccionó el $70 \%$ de las unidades pertenecientes a cada una de estas temáticas. Se buscó respetar la representatividad cuantitativa que tienen en el muestreo inicial las tres cuentas y el porcentaje de unidades con imágenes por tópico. Consecuentemente, nuestro corpus principal quedó compuesto por 1065 unidades, el 20\% (218) de las cuales presenta al menos una imagen.

\subsection{Análisis del corpus}

La perspectiva adoptada propone, en primer lugar, llevar a cabo un análisis descriptivo y multidimensional del corpus que considere tanto aspectos gramaticales, como pragmáticos. Para organizarlo, recurrimos a dos softwares de anotación y exploración de corpus: UAM Corpus Tool 3.3 (M. O’Donnell 2007a) - para el análisis del modo verbal-y UAM Image Tool (M. O’Donnell 2007b) para el etiquetado de las imágenes-. Se trata de programas diseñados especialmente para el desarrollo de investigaciones lingüístico/discursivas de base sistémico funcional. El primero trabaja sobre texto plano y el segundo, sobre archivos jpg. Ambos permiten el etiquetado de corpus a partir de esquemas diseñados por el analista (en el caso del primero de oraciones, cláusulas o partes de ellas y en el del segundo, de fragmentos de cada imagen seleccionados por el investigador). En nuestro estudio, configuramos esquemas basados en las categorías propuestas por las teorías que se presentarán a continuación. El etiquetado fue realizado en su totalidad por la investigadora a cargo del proyecto 
con la supervisión de sus directores. El empleo de estos programas simplifica y ordena el análisis del corpus y permite, además, filtrar y cruzar datos. No obstante, dada la gran cantidad de unidades con la que trabajamos, y la necesidad de observar los análisis aplicados de manera simultánea sobre el total del corpus y de exponerlos en un formato accesible, se decidió exportarlos a Excel.

Hecha esta aclaración respecto de los programas empleados, pasaremos a describir el proceso de análisis propiamente dicho. Para el estudio gramatical, el primer paso consiste en segmentar las unidades del modo verbal (secuencias o tuits) en cláusulas -unidad mínima en la cual se proyectan simultáneamente las tres metafunciones del lenguaje (Halliday y Matthiessen 2014)- y numerarlas a fines de organizar el estudio. Respecto de las imágenes, consideramos a cada una de ellas como una unidad mínima, en la que se articulan diversos modos semióticos y también se proyectan las metafunciones (Kress y Van Leeuwen 2006 [1996]).

Una vez obtenidas las unidades de análisis, se desarrolla el estudio del sistema de transitividad. Para ello, clasificamos los procesos seleccionados, tanto en las cláusulas como en las imágenes, y sus participantes asociados, guiándonos por las seis clases de procesos identificadas por la lingüística sistémico funcional (Halliday y Matthiessen 2014). Para complementar el análisis de esta función, proponemos además identificar qué rol ocupan los actores sociales representados (el candidato, el adversario, el partido, los paradestinatarios, otros), y si se los presenta explícitamente, elididos (Halliday y Hasan 1976) o aludidos (Lavandera 1985).

En segunda instancia, analizamos el sistema de modo. Con esta finalidad, etiquetamos las cláusulas según: su función de habla y las clases de intercambio que realizan: demanda u oferta de acción o de información (Halliday y Matthiessen 2014), los modos verbales, y la polaridad. El estudio de la función interpersonal en las fotografías se lleva a cabo, a partir de la propuesta de Kress y Van Leuween (2006 [1996]), a través del análisis de la mirada (si se orienta o no al espectador), el encuadre (cuán cerca se representa el objeto fotografiado) y el punto de toma (a nivel, picado, contrapicado, etc.), lo cual permite dar cuenta de la clase de intercambio, la distancia social y las relaciones de poder representadas entre el motivo fotografiado y el espectador.

La tercer función del lenguaje a considerar en el análisis gramatical es la textual. Para nuestro estudio hemos decidido centrarnos, especialmente, en el análisis del sistema de tema y, en particular, en la identificación de lo que se denominan temas marcados: es decir aquellos casos en los que la información que ocupa el primer lugar en la cláusula no es la habitual en esa posición en las cláusulas en 
español (Halliday y Matthiessen 2014), por lo cual adquiere una saliencia especial.

Para el estudio de los recursos pragmáticos - que en combinación con los gramaticales nos permiten reconstruir estrategias- abordamos, en primera instancia, el análisis de la valoración (Martin y White 2005), una perspectiva semánticodiscursiva diseñada como complemento del sistema de modo. A partir de la misma, estudiamos el posicionamiento del sujeto discursivo frente a aquello que plantea (actitud invocada o inscripta), codificado en terminos de afecto, juicio o apreciación (y sus subclases) y cuáles son las entidades valoradas. Asimismo, analizamos el carácter monoglósico o heteroglósico (expansivo o contractivo) de cada enunciado, y buscamos reponer las fuentes de los discursos con los que se establece heteroglosia (adversarios, copartidarios, medios masivos, otros) y cómo se las presenta: explícitamente, aludidas o presupuestas. En este análisis, incluimos el de recursos propios de Twitter que colaboran con la función interpersonal y, en particular, con la heteroglosia: los hashtags, menciones, retuiteos y marcas para señalar la presencia del discurso referido (como el asterisco). Finalmente, señalamos elementos semántico-discursivos que producen graduación de la fuerza y el foco de las valoraciones. Al estudiar las fotografías, podemos dar cuenta de las valoraciones mediante el análisis de la escena construida, los colores seleccionados y la gestualidad y postura de los participantes, entre otros recursos.

Luego, se analizan los supuestos e inferencias. Para ello, se da por sentado el respeto del principio de relevancia (Sperber y Wilson 1994 [1986] ). En cada enunciado estudiamos la información que el sujeto discursivo presenta como parte del conocimiento de fondo compartido con los lectores (supuestos) y aquella que se espera que el lector infiera mediante una implicatura pragmática directa o indirecta (Wilson y Sperber 1981). Esta información es explicitada entre corchetes para señalar que es repuesta por el analista. Siguiendo a Fairclough (2003), quien señala la relevancia ideológica que tiene dar por supuesta determinada clase de información, proponemos complementar este análisis mediante la identificación de la clase de supuestos: de existencia, de valores o proposicionales.

Una vez desarrollados los análisis descriptivos hasta aquí presentados, se ponen en relación sus resultados a los fines de buscar recurrencias en la combinación de recursos gramaticales y pragmáticos que den lugar a la reconstrucción de estrategias discursivas. Las mismas son explicadas en relación con los contextos en los que se han producido los mensajes y las intenciones comunicativas que se considera que los participantes poseen en dichos contextos. Consideramos que en nuestro caso, al explicar las estrategias discursivas desplegadas por los candidatos durante la campaña, podremos diferenciar: un conjunto tendiente a construir la imagen del candidato, otras desarrolladas con el fin de amenazar la imagen del 
adversario y/o polemizar con él y un tercer conjunto destinado a defender la postura del candidato respecto de determinados temas que hacen a la agenda política. Esta dimensión del estudio nos permite concentrar todos los recursos semióticos desplegados por los candidatos en un número acotado de estrategias mediante las cuales accedemos a explicar de qué manera se construye un discurso político de campaña en Twitter.

Luego de explicadas las estrategias discursivas identificadas, se procede a su análisis interpretativo crítico. Para ello, se relacionan los resultados del estudio previo con: las características propias de la red social, la naturaleza del discurso político actual y su mediatización en redes sociales, el diálogo con los medios tradicionales y hechos particulares de la coyuntura política argentina que pueden haber impactado en las estrategias desarrolladas, entre otros. A partir de ello, se busca definir las particularidades de la campaña presidencial en Twitter como práctica discursiva y el impacto de la adopción de esta red social en las prácticas políticas actuales.

\section{Conclusión}

El discurso de campaña producido en las cuentras oficiales de Twitter de los candidatos presidenciales constituye una nueva práctica discursiva que debe ser estudiada desde diversas perspectivas para contribuir a la comprensión de las prácticas políticas actuales. Consideramos que el análisis estratégico del discurso con una perspectiva multimodal y crítica resulta un enfoque adecuado para abordar este nuevo objeto de estudio, dado que sus tres etapas de investigación -descriptiva, explicativa e interpretativa- permiten entender cómo los usuarios de estas cuentas optan y combinan estratégicamente recursos gramaticales y pragmáticos pertenecientes a diversos modos semióticos a los fines de alcanzar determinados objetivos discursivos.

En este estudio, presentamos una metodología, constituída en base a esta perspectiva, para la conformación y análisis de un corpus de discursos políticos de campaña producidos en Twitter. Se buscó dar cuenta de nuestras preguntas y decisiones metodológicas y de las herramientas que estamos adoptando en nuestro trabajo en curso. Se espera que las mismas puedan aportar a la discusión respecto de las metodologías empleadas para analizar discursivamente nuevos fenómenos que nos interpelan como investigadores. Nos interesa, especialmente, destacar la perspectiva multimodal adoptada en nuestra investigación, que no parece ser te- 
nida en cuenta en muchos de los estudios relevados que toman al discurso producido en la red de microblogueo como objeto de estudio, y que consideramos fundamental para el abordaje de un corpus como el presentado.

La aplicación de esta metodología se encuentra en proceso, lo cual podría llevar a posteriores reformulaciones. Asimismo, resultaría interesante, para futuros estudios, probar su aplicación en otros corpus de discursos multimodales breves.

\section{Referencias}

Alcántara-Plá, M. \& Ruiz-Sánchez, A. 2018. Not for Twitter: Migration as a silenced topic in 2015 Spain General. In M Schröter \& Ch Taylor (eds.). Exploring Silence and Absence in Discourse: Empirical Approaches. London: Palgrave Mc Millan,

Beaulieu, A. \& Estalella, A. 2012. Rethinking research ethics fir mediated settings. Information, Communication \& Society 15 (1): 23-42.

Calvo, E. 2015. Anatomía política de Twitter en Argentina. Tuiteando \#Nisman. Ciudad Autónoma de Buenos Aires: Capital Intelectual.

De Matteis, L. 2014. Ejes para un debate sobre el uso ético de datos interaccionales escritos y orales obtenidos en línea. In Actas de las I Jornadas de Humanidades Digitales. Buenos Aires, 235-247.

Delany, C. 2009. Learning from Obama: Lessons for Online Communicators in 2009 and Beyond. Kindle editions.

Ess, C. \& Jones, S. 2004. Ethical Decision-Making and Internet Research: Recommendations from the AOIR Ethics. In E. Buchanan (ed.) Ethics Issues and controversies. Hershey London - Melbourne - Singapore: Information Science Publishing, 27-44.

Fages-Ramió, R. 2008. Actitud 2.0: la política más allá de los blogs. IDP Revista de Internet, Derecho y Política: Monográfico «IV Congreso Internet, Derecho y Política (IDP). Software social y Web 2.0: Implicaciones jurídico-políticas» 1(7): 19-25.

Fairclough, N. 1993. Discourse and Social Change. Cambridge - Oxford: Black well Publishers.

Fairclough, N. 2000. Representaciones del cambio en el discurso neoliberal. Cuaderno de relaciones laborales: 13-35.

Fairclough, N. 2003. Analysing Discourse: Textual Analysis for Social Research. Londres: Routledge.

Goffman, E. 1970 [1967] Ritual de la interacción. Buenos Aires: Tiempo Contemporáneo.

Graham, T. Broersma, M. Hazelhoff, K. \& van'T Haar, G. 2013. Between broadcasting political massages and interacting with voters. London: Routledge.

Halliday, M. A. K. 1970. Estructura y función del lenguaje. In J. Lyons (ed.), Nuevos horizontes de la lingüística. Madrid: Alianza,.

Halliday, M. A. K. 1985. An Introduction to Functional Grammar. Londres: Edward Arnold.

Halliday, M. A. K. \& Hasan, R. 1976. Cohesion in English. London: Longman.

Halliday, M. A. K. \& Matthiessen, C. 2014. Hallidya's introduction to functional grammar. Fourth edition. London y New York: Routledge.

Hine, C. 2004. Etnografía virtual. Barcelona: Editorial UOC. 
Jungherr, A. 2016. Twitter use in election campaigns: A systematic literature review. Journal of information technology \& politics 13 (1): 72-91.

Kress, G \& Van Leeuwen. 2001. Multimodal Discourse. Great Britain: Hodder Arnold.

Kress, G \& Van Leeuwen, T. 2002. Visual comunication. Londres: SAGE publications.

Kress, G. \& Van Leeuwen, T. 2006 [1996]. Reading images. Londres: Routledge.

Lavandera, B. 1985. Decir y aludir: una propuesta metodológica. Cuadernos del Instituto de Lingüística (Filología) 1 (1): 21-31.

Mancera Rueda, A. \& Pano Alamán, A. 2013. El discurso político en Twitter: Análisis de mensajes que "trinan". Barcelona: Anthropos Editorial.

Mangone, C. 2012. Apuntes sobre el discurso político actual. In C. Mangone \& J. Warley (eds), El discurso político. Del foro a las redes. Ciudad Autónoma de Buenos Aires: Biblos, 291300 .

Markham, A. \& Buchanan, E. 2012. Ethical Decision-Making and Internet Research: Recommendations from the AoIR Ethics Working Committee (Version 2.0). http://www.aoir.org/reports/ethics.pdf (accessed March 20, 2018).

Mazzuchino, M. G. 2017. Twitter como espacio (¿anti?)político: análisis discursivo de los tuits del presidente Mauricio Macri. RALED 17 (2): 66-82.

Martin, J. \& White, P. 2005. The Language of Evaluation, Appraisal in English. Londron: Palgrave Macmillan.

Menéndez, S. M. 2000. Recursos y estrategias discursivas. Selección y dependencia de los procesos en el discurso sobre la propaganda del SIDA. In Revista Argentina de Lingüística: 213-227.

Menéndez, S. M. 2005. ¿Qué es una estrategia discursiva? In Actas del Congreso Internacional: Debates Actuales. Las teorías críticas de la literatura y la lingüística. Buenos Aires: FFyL UBA.

Menéndez, S. M. 2009. Estrategias, registros y géneros discursivos: de la realización a la recurrencia. In Actas del IV Coloquio de Investigadores en estudios del discurso. Córdoba: Universidad Nacional de Córdoba.

Menéndez, S. M. 2010. Opción, registro y contexto. El concepto de significado en la lingüística sistémico funcional. In Tópicos del seminario. 23: 221-239.

Menéndez, S. M. 2012. Multimodalidad y estrategias discursivas: un abordaje metodológico. In Revista Latinoamericana de estudios del discurso 12 (1): 57-73.

O’Donnell, M. 2007a. UAM Corpus Tool 3.3. Madrid.

O’Donnell, M. 2007b. UAM Image Tool. Madrid.

Orihuela, J. L. 2013. Mundo Twitter. Barcelona: Alienta.

Ques, M. 2012. Retóricas de la proximidad: los tweets presidenciales en Argentina. In M. Braun (ed.) Revista latinoamericana de Opinión Pública. 2. Ciudad Autónoma de Buenos Aires: Teseo.

Raiter, A. 2009. "Hablo y entiendan": creencias, presuposición e interdiscurso en los actos de Cristina Fernández de Kirchner. Oralia 12: 73-96.

Rivers, C. \& Lewis, B. 2014. Ethical research standards in a world of big data. F1000Research 3 (38).

Rojas, D. 2012._argentuits. Pasiones políticas en 140 caracteres. Ciudad Autónoma de Buenos Aires: Planeta.

Sarlo. B. 2011. La audacia y el cálculo. Kirchner 2003 - 2010. Buenos Aires: Sudamericana. 
Slimovich, A. 2014. El discurso macrista en Twitter. Un análisis sobre la campaña para la reelección del jefe de gobierno de Buenos Aires. In Revista de estudios políticos y estratégicos: 8-27.

Sperber, D. \& Wilson, D. 1994 [1986]. La relevancia. Comunicación y procesos cognitivos. Madrid: Visor.

Twitter. 2018. Política de Privacidad de Twitter. https://twitter.com/es/privacy\#update (accessed May 2018).

Veron, E. 2012. Mediatización de la política: estrategias, actores y construcción de colectivos. In A. Mercier. La comunicación política. CABA: La Crujía. 63-72.

Wilson, D. \& Sperber, D. 1981. On Grice's theory of conversation. In P Werth (ed.), Conversation and Discourse. Londres: Croom Helm, 155-17

\section{Agradecimientos}

Este artículo ha sido realizado con el apoyo de una beca doctoral de CONICET. Agradezco a mi director Salvio Martín Menéndez, cuyo seguimiento y asesoramiento han contribuido significativamente a este trabajo. Asimismo, se agradece a los evaluadores anónimos de este escrito, cuyas correcciones, observaciones y generosos aportes enriquecieron notablemente la propuesta inicial. 